DOI: $10.14720 /$ aas.2016.107.2.23

Agrovoc descriptors: Slugs, noxious molluscs, mollusc control, pest control, control methods, ecological control, cultural pest control

Agris category code: $\mathrm{H} 01, \mathrm{~h} 10$

\title{
Možnosti okoljsko sprejemljivega zatiranja gospodarsko škodljivih polžev s poudarkom na rezultatih domačih raziskav zatiranja lazarjev (Arionidae)
}

\author{
Žiga LAZNIK ${ }^{1}$, Stanislav TRDAN ${ }^{2}$
}

Received July 15, 2016; accepted September 30, 2016.

Delo je prispelo 15. julija 2016, sprejeto 30. septembra 2016.

\section{IZVLEČEK}

Polže uvrščamo med gospodarsko pomembne škodljivce gojenih in samoniklih rastlin. Škodljivi so predvsem polži brez hišic, ki jih uvrščamo v družini lazarjev (Arionidae) in slinarjev (Limacidae). Polži so vsejede živali. Občutljivi so na izsušitev, zato so aktivni ponoči in $\mathrm{v}$ oblačnem, deževnem vremenu. Gospodarsko škodo povzročajo na vrtninah, poljščinah, sadnem drevju, grmovnicah, travi, zeliščih in okrasnih rastlinah. Prvi zapisi o zatiranju polžev segajo v začetek 20. stoletja. Sledilo je pomembno odkritje v letu 1934, ko so v Južni Afriki odkrili metaldehid, ki je prinesel pomemben napredek $\mathrm{v}$ varstvu rastlin pred polži. Naslednji pomemben korak $\mathrm{v}$ razvoju limacidov je bil dosežen $\mathrm{Z}$ odkritjem karbamatov. Zaradi dokazanega neciljnega delovanja metaldehida in ostalih snovi $\mathrm{z}$ limacidnim delovanjem raziskovalci iščejo alternativne rešitve $\mathrm{v}$ varstvu rastlin pred polži. V prispevku predstavljamo različne okoljsko sprejemljive načine zatiranja polžev, kot so ustrezna obdelava tal, nastavljanje pasti $\mathrm{s}$ pivom, postavljanje prehodnih ovir in uporaba t.i. elektroograj, s poudarkom na rezultatih domačih raziskav zatiranja lazarjev.

Ključne besede: polži, zatiranje, okoljsko sprejemljivi načini

\author{
ABSTRACT \\ POSSIBILITIES OF ENVIRONMENTALLY \\ ACCEPTABLE CONTROL METHODS AGAINST \\ ECONOMICALLY IMPORTANT SLUGS WITH \\ EMPHASIS ON THE RESULTS OF DOMESTIC \\ RESEARCHES OF CONTROLLING ARIONIDAE \\ SLUGS
}

Slugs from the Arionidae and Limacidae families are classified as an important economic agricultural pests. They are omnivorous animals. Slugs are sensitive to drying out, so they are active at night and in cloudy, rainy weather. They cause economic damage to the vegetables, crops, fruit trees, shrubs, grasses, herbs and ornamental plants. First reports of slugs control are dating from the early $20^{\text {th }}$ century. This was followed by an important discovery in the year 1934 when in South Africa metaldehyde was discovered. This discovery has brought significant progress in the protection of plants against slugs. The next major step in the development of molluscicides was achieved with the discovery of carbamates. Due to the proven non-target effect of metaldehyde and other substances with molluscicidal activity researchers are looking for alternative solutions in the protection of plants against slugs. In this paper we present a variety of environmentally acceptable methods of slugs control, such as proper soil cultivation, beer trapping, barriers and the use of so-called electrical fences against slugs.

Key words: slugs, control, environmentally acceptable methods

\section{UVOD}

Številčnost lazarjev (Arionidae) se je v zadnjih letih močno povečala. Čeprav so ti polži gospodarsko zelo škodljivi (Frank, 1998;
Hammond in sod., 1999; Ahmadi, 2004), pa imajo $\mathrm{v}$ naravi pomembno vlogo pri ohranjanju biološkega ravnovesja, saj se hranijo z različnimi

\footnotetext{
doc. dr., univ. dipl. inž. agr, Jamnikarjeva 101, SI-1000 Ljubljana, e-mail: ziga.laznik@bf.uni-lj.si

2 prof.. dr., prav tam
} 
rastlinskimi in živalskimi ostanki (Burnie, 2001; Ortan, 2014). Polže uvrščamo med gospodarsko pomembne škodljivce, še posebno $\mathrm{v}$ letih in razmerah, ki so za njih ugodna (mile zime, leta $\mathrm{z}$ veliko dežja). Gospodarsko škodo v večji meri povzročajo le polži brez hišic (Godin, 1983; Laznik in sod., 2011). To so predstavniki iz družin lazarjev (Arionidae) in slinarjev (Limacidae) (Milevoj, 2007).

Polži so občutljivi na izsušitev, zato so aktivni ponoči in $\mathrm{v}$ oblačnem, deževnem vremenu. Večina se prehranjuje s svežimi in odmrlimi rastlinskimi deli. Zelo radi se hranijo z mladimi rastlinami, npr. sadikami. Škodo povzročajo na vrtninah, poljščinah, sadnem drevju, grmovnicah, travi, zeliščih in okrasnih rastlinah (Godin, 1983). Ob množičnem pojavu lahko polži povzročijo velik izpad pridelka. S hranjenjem na rastlinah, kar je vidno $\mathrm{v}$ obliki manjših ali večjih luknjic, povzročajo količinski in kakovostni izpad pridelka (Milevoj, 2007).

\section{DEJAVNIKI, KI VPLIVAJO NA POJAV POLŽEV}

Pojavljanje lazarjev vzpodbuja gojenje rastlin $\mathrm{v}$ monokulturah in uporaba fitofarmacevtskih sredstev, ki omejujeta številčnost naravnih sovražnikov na takšnih območjih (Milevoj, 2007). Podobno velja za izsuševanje vlažnih biotopov, kar prizadane naravne sovražnike polžev (Dmitrieva, 1978). Populacije polžev se večajo tudi zaradi opustitve gojitve perutnine na prostem, ki se hrani z jajčeci polžev. Pojav polžev je večji ob milih zimah in vlažnih poletjih. Zelo dobra skrivališča zanje so neobdelana zemljišča, zeleni pasovi ob prometnicah, zarasla, zapleveljena ter mulčena zemljišča. Njihovo število se poveča ob pretirani uporabi dušika na zemljiščih (Milevoj, 2007).
Pojav lazarjev zaznamo že zgodaj spomladi, ko se temperature dvignejo nad $5{ }^{\circ} \mathrm{C}$. Mladi lazarji se iz jajčec izležejo marca ali aprila. $\mathrm{Na}$ začetku ostanejo blizu svojih skrivališč in se z rastlinskimi ostanki hranijo le $\mathrm{v}$ neposredni bližini skrivališč. Število lazarjev se začne hitreje večati v sredini aprila, ko povprečna dnevna temperatura doseže $10{ }^{\circ} \mathrm{C}$ (Young in Port, 1989). Od začetka do sredine maja populacija doseže prvi vrh. Lazarji se nato selijo in intenzivno iščejo hrano, kar jim omogoča hitro rast. Drugi vrh populacije dosežejo nekje med začetkom in sredino avgusta. Večja populacija lazarjev se pogosto pojavi tudi konec septembra, včasih pa šele v sredini oktobra (Kozlowski in Sionek, 2000).

\section{3 ŠKODLJIVOST}

Gospodarsko škodljivi so predvsem polži brez hišice, in sicer predstavniki dveh družin: lazarji (Arionidae) in slinarji (Limacidae). Že nekaj polžev na kvadratni meter lahko povsem uniči pridelek (Milevoj, 2007; Laznik in Trdan, 2009). Lazarji spadajo med pljučarje in polifage, ki se hranijo s široko paleto živil. Pasejo se na razpadajočih zelenih delih rastline in na rastočih organizmih, kot so glive, alge, mah, šotišče in lišaji (Kozlowski in Kozlowska, 1998; Kozlowski, 2000). Njihova osnovna hrana so gojene in divje rastoče rastline. Najraje se hranijo z novo rastočimi rastlinami (s kaljenimi semeni, sadikami, listi, vejicami, koreninami, sadjem) in pogosto povzročajo poškodbe na posevkih, zlasti na mladih komaj posajenih rastlinah (Esenko, 2008). Opravljen je bil poskus, v katerem so opazovali, s katerimi rastlinami se lazarji najraje prehranjujejo. Največ poškodb je bilo zabeleženih na vrtni solati, zelju, korenju, rdeči pesi, redkvici, peteršilju in fižolu, medtem ko je bilo na sončnicah, detelji in krompirju poškodb najmanj. Poškodbe so bile zabeležene tudi na okrasnih rastlinah, zeliščih in jagodnjaku(Kozlowski in Kozlowska, 1998; Kozlowski, 2000). 


\section{ZATIRANJE}

Za uspešno zatiranje polžev moramo najprej ugotoviti, kakšno škodo povzročajo ter kolikšen je njen obseg (Laznik in Trdan, 2009). Pri odločanju o izbiri načina zatiranja polžev je poleg stroškov zatiranja pomembna tudi njegova okoljska neoporečnost. Včasih se lahko pred polži uspešno obvarujemo že z ustrezno obdelavo tal, kolobarjenjem, pravočasno in kakovostno setvijo ipd. (Vakselj, 1992). Lahko si pomagamo z različnimi biotičnimi varstvenimi ukrepi, če pa z navedenimi ukrepi nismo učinkoviti, lahko uporabimo še kemične načine zatiranja. Zaradi jesenskega odlaganja jajčec je zelo priporočljivo zatirati polže tudi jeseni, ker tako zmanjšamo njihovo spomladansko populacijo (Ortan, 2014). Žal pa v jesenskem času ljudje na polže pogosto pozabijo, saj se ti zaradi nižjih temperatur poskrijejo $\mathrm{v}$ svoja skrivališča in so zato slabše opazni.

Uporaba prvih vab sega v leto 1899 , ko so začeli proti polžem nastavljati vabe $\mathrm{z}$ bakrovim acetoarzenatom ter ostalimi bakrovimi in arzenovimi spojinami. Od leta 1939 so bile v uporabi vabe $\mathrm{z}$ raznimi anorganskimi solmi, na primer $\mathrm{z}$ barijevim, kalcijevim in natrijevim fluorsilikatom. Leta 1934 so v Južni Afriki odkrili metaldehid, ki je prinesel pomemben napredek pri zatiranju polžev (Henderson in Triebskorn, 2002). Naslednji velik korak v razvoju je bil dosežen $\mathrm{s}$ karbamati: izolanom, sevinom, metiokarbom, kloetokarbom, tiodikarbom in bensultapom. Izvedene so bile tudi raziskave s kofeinom, ki je kot čisti koncentrat sicer zelo strupen, celo bolj kot metaldehid (Hata in sod., 1997). V devetdesetih letih prejšnjega stoletja so ponovno začeli raziskovati učinkovitost vab na osnovi različnih kovin (železo, aluminij) in organskih nosilcev. V poljskih poskusih so se za najbolj učinkovite pripravke izkazale snovi $\mathrm{z}$ metaldehidom in karbamati (Henderson in Triebskorn, 2002).

Pri zatiranju polžev na vrtovih, kjer se velikokrat prerazmnožijo, je pomembno, da tla obdelujemo in za vrt redno skrbimo (Vakselj, 1992). Pazimo na razpoke, ki nastanejo $\mathrm{v}$ tleh, saj te polžem omogočajo idealno zatočišče in skrivališče za odlaganje jajčec. Koristno je, da jih čim prej zasujemo. V primeru težkih tal je priporočljivo jeseni počakati na prvo zmrzal, nato pa tla preorati.
Spomladi pa tla čim prej zrahljamo in uničimo skrivališča, s čimer spravimo jajčeca iz skrivališč na površje, kjer se hitro posušijo (Dmitrieva, 1978). Koristno je tudi, da v območju okrog vrta pokosimo travo, ki prav tako predstavlja ustrezno zatočišče za polže. Izogibamo se prepogostemu zastiranju s pokošeno travo, saj travna zastirka prav tako predstavlja idealno zatočišče za polže (Dmitrieva, 1978). Spomladi, ko začnemo s setvijo in sajenjem rastlin, je pomembno, da to storimo pravočasno, in sicer takrat, ko imajo rastline dobre razmere za rast. S tem rastlinam omogočimo, da hitro (z)rastejo in so manj časa $v$ občutljivi fazi (Purvis, 1996).

Ročno pobiranje polžev se izvaja $\mathrm{v}$ zgodnjih jutranjih urah ali pa zvečer in ob deževnem vremenu, ko so polži aktivni skozi ves dan. Ta metoda je bolj primerna za majhna zemljišča, na večjih zemljiščih je pobiranje prenaporno (Esenko, 2008). Precej učinkovito metodo za zmanjševanje škodljivosti polžev na manjših površinah predstavljajo tudi vabe s pivom (Ortan, 2014). V tla vkopljemo jogurtov lonček, napolnjen s pivom. Lončka ne napolnimo do vrha, da polži zlezejo $\mathrm{v}$ lonček in se v pivu utopijo. Za zmanjšanje škode, ki jo napravijo polži, si lahko pomagamo tudi s postavitvijo ovir (Schüder in sod., 2003). Namen ovir je, da polžem prepreči hranjenje in povzročitev poškodb na gojenih rastlinah. Namestimo jih med mestom, kjer se polži skrivajo in mestom, kjer se hranijo. $\mathrm{V}$ ta namen uporabljamo pripravke, ki polže izsušujejo in povzročajo močno izločanje sluzi (Prior, 1985). Ker se $\mathrm{z}$ izločanjem sluzi polži $\mathrm{v}$ kritičnih razmerah zaščitijo le enkrat, mora biti takšna ovira dovolj široka. Po tleh lahko potrosimo lesni pepel ali apno, in sicer v debelini od 1 do $3 \mathrm{~cm}$ (Resnik, 2015). Oba pripravka sta higroskopična, povzročata izsušitev in izločanje sluzi (Schüder in sod., 2003). Učinek je viden le ob suhem vremenu. Priporočljiva širina varovalnega pasu je od 10 do $20 \mathrm{~cm}$. Poraba žganega apna je od $20 \mathrm{do} 30 \mathrm{~kg} / \mathrm{ar}$ (Vakselj, 1992; Resnik, 2015).

Žgano apno ali apneni dušik lahko uporabimo tudi drugače, in sicer tako, da ga potrosimo po talnem površju (Vakselj, 1992). Zemljišče najprej pokosimo in odstranimo pokošeno gmoto. Pozno zvečer ali zgodaj zjutraj ob suhem ali rahlo 
vlažnem vremenu apno oziroma apneni dušik potrosimo $\mathrm{v}$ dveh odmerkih, od 3 do $4 \mathrm{~kg} / \mathrm{ar}$ žganega apna oziroma od 1,5 do $2 \mathrm{~kg} / \mathrm{ar}$ apnenega dušika. Med nanosoma počakamo vsaj od 15 do 30 min. Snovi morata priti $\mathrm{v}$ neposreden stik s polži (Resnik, 2015).

Apneni dušik je iz naravnih sestavin: apnenca, premoga in zračnega dušika. Dokazano je bilo, da je mogoče $z$ redno uporabo tega gnojila uspešno zmanjšati pojav nekaterih talnih škodljivcev (strun [Agriotes spp.]) in bolezni (golšavost kapusnic [Plasmodiophora brassicae Woronin], bela gniloba [Sclerotinia sclerotiorum (Lib.) de Bary]), prav tako pa lahko vplivamo tudi na trajno zmanjšanje populacije polžev ter manjšo zapleveljenost. Posebnost gnojila je počasno sproščanje dušika, ki se ne izpira ob močnih padavinah. Rastlina poleg dušika sprejme tudi kalcij, ki rastlinam omogoča večjo odpornost na bolezni in škodljivce. $Z$ uporabo apnenega dušika ne spreminjamo bistveno $\mathrm{pH}$ tal, lahko pa celo zmanjšamo njihovo kislost (Šušek, 2015). Da čim bolj učinkovito zatremo polže, je priporočljivo apneni dušik posuti od 8 do 10 dni pred sajenjem. Takrat imajo polži brez hišice nezavarovano mehko telo, ki je zelo občutljivo za poškodbe in jedke snovi. Dokazano je, da so mladi polži in jajčeca zelo občutljivi za gnojenje $\mathrm{z}$ apnenim dušikom (Ryder in Bowen, 1977). Pri uporabi $30 \mathrm{~g}$ apnenega dušika $/ \mathrm{m}^{2}$ je bilo dva dni po nanosu živih polžev samo $24 \%$, pri količini $50 \mathrm{~g} / \mathrm{m}^{2}$ pa je bilo preživelih polžev le še $11 \%$. Pozorni moramo biti samo pri razgradnji gnojila, kjer nastajajo plini, ki so fitotoksični in lahko do neke mere delujejo fungicidno in herbicidno (Šušek, 2015).

f Med naravne sovražnike polžev uvrščamo race. $\mathrm{Za}$ najučinkovitejše so se izkazale pekinška, indijska ali domača raca (Ortan, 2014). Poskrbeti moramo, da imajo na voljo dovolj vode, saj imajo polži slinasto telo in bi zaradi tega lahko škodljivo vplivali na prebavni trakt živali. Pomagajo nam lahko tudi domače kokoši, ki se hranijo z jajčeci polžev, ki jih polži odložijo v tla (Vakselj, 1992).

Za enega od uspešnih načinov biotičnega zatiranja polžev se je $\mathrm{v}$ tujini že izkazala tudi uporaba parazitske ogorčice Phasmarhabditis hermaphrodita (Schneider) (Wilson in sod., 1993). Pripravek je patentiran pod uradnim imenom Nemaslug ${ }^{\circledR}$. Parazitske ogorčice polžev trenutno prodajajo v 14-ih evropskih državah. V Sloveniji parazitskih ogorčic polžev za te namene še nismo uporabljali in preučevali, saj je omejena vrsta še vedno na seznamu t.i. tujerodnih organizmov (Laznik in sod., 2009; Resnik, 2015).

\section{REZULTATI DOMAČIH RAZISKAV}

V laboratorijskem poskusu smo na Biotehniški fakulteti $\mathrm{v}$ Ljubljani preučevali učinkovitost delovanja izbranih okoljsko sprejemljivih snovi pri zatiranju lazarjev in raziskali potencialne možnosti uporabe teh snovi za omejevanje njihovega škodljivega delovanja na gojenih rastlinah. V poskus smo vključili naslednje snovi: lesni pepel, hidrirano apno, diatomejsko zemljo in žagovino. Njihov vpliv smo preučevali posamično ali $\mathrm{v}$ kombinaciji. Izvedli smo dva poskusa, in sicer kontaktni učinek posamezne snovi ali kombinacije snovi pri valjanju in učinek postavitve prehodne ovire. Ob stiku s snovjo so se lazarji v trenutku skrčili in začeli močno izločati sluz. Tretiranega polža smo položili v petrijevko, ki je vsebovala list solate in vlažen tampon. Največjo smrtnost preučevanih polžev smo ugotovili pri uporabi hidriranega apna, kjer so lazarji v trenutku poginili. Tudi $\mathrm{v}$ drugem poskusu, $\mathrm{v}$ katerem smo na sredino posode položili svež list solate in vlažen tampon, okrog pa posuli različne preučevane snovi, se je za najučinkovitejšo oviro lazarjem izkazalo hidrirano apno oziroma kombinacija hidriranega apna $\mathrm{z}$ drugimi snovmi (Resnik, 2015).

V letih 2008 in 2009 smo v laboratorijskih razmerah preizkušali limacidno delovanje 26 snovi v 89 različnih obravnavanjih (Mihičinac, 2010). Poskusi, v katere smo vključili lazarje (Arion spp.), so potekali $\mathrm{v}$ dveh serijah, in sicer $\mathrm{z}$ injiciranjem aktivne snovi $\mathrm{v}$ prebavilo polžev in $\mathrm{z}$ uporabo pelet. V naši raziskavi smo pri injiciranju $100 \%$ smrtnost polžev ugotovili $\mathrm{v}$ obravnavanju $\mathrm{z}$ bakterijo Bacillus thuringiensis Berliner 1915 var. kurstaki $(0,25 \mathrm{ml} \mathrm{v} 10 \%$ koncentraciji/osebek), kofeinom $(0,25 \mathrm{ml} \mathrm{v} 10 \%$ koncentraciji/osebek), natrijevim dodecil sulfatom $(0,25 \mathrm{ml}$ v $10 \%$ koncentraciji/osebek; $\quad 0,125 \mathrm{ml} \quad \mathrm{v} \quad 10 \%$ 
koncentraciji/osebek; $\quad 0,125 \quad \mathrm{ml} \quad \mathrm{v} \quad 5 \%$ koncentraciji/osebek; $0,0625 \mathrm{ml} \quad \mathrm{v} \quad 10 \%$ koncentraciji/osebek) in pirimikarbom $(0,25 \mathrm{ml} \mathrm{v}$ $10 \%$ koncentraciji/osebek; $0,125 \mathrm{ml} \quad \mathrm{v} \quad 10 \%$ koncentraciji/osebek; $\quad 0,125 \quad \mathrm{ml} \quad \mathrm{v} \quad 5 \%$ koncentraciji/osebek; $\quad 0,0625 \mathrm{ml} \quad \mathrm{v} \quad 10 \%$ koncentraciji/osebek), medtem ko smo največjo $(100 \%)$ smrtnost polžev pri uporabi pelet dosegli z natrijevim dodecil sulfatom $\mathrm{v} 0,5 \%$ koncentraciji $\mathrm{z}$ dodatkom kumine (Mihičinac, 2010).

$\mathrm{V}$ laboratorijskem poskusu smo $\mathrm{z}$ metodo vbrizgavanja v prebavilo lazarjev (Arion spp.) preizkušali limacidno učinkovitost štirih različnih snovi: pripravkov Delfin WG in Pirimor 50 WG ter kofeina in natrijevega dodecil sulfata (Verlič, 2012). Učinkovitost smo preizkušali pri štirih različnih koncentracijah $(1,25 ; 2,5 ; 5 ; 10 \%)$ in v treh različnih odmerkih $(0,062 ; 0,125 ; 0,25 \mathrm{ml})$. Največji limacidni potencial je imel natrijev dodecil sulfat, ki je pokazal zadovoljivo delovanje že pri manjših koncentracijah. Pri vbrizgavanju smo $100 \%$ smrtnost lazarjev ugotovili v obravnavanjih s pripravkom Delfin WG $(0,25 \mathrm{ml} v$ $10 \%$ koncentraciji, $0,25 \mathrm{ml}$ v $5 \%$ koncentraciji in $0,25 \mathrm{ml}$ v $2,5 \%$ koncentraciji), $\mathrm{z}$ natrijevim dodecil sulfatom $(0,25 \mathrm{ml}$ v $10 \%$ koncentraciji, $0,125 \mathrm{ml}$ $10 \%$ koncentraciji, $0,062 \mathrm{ml}$ v $10 \%$ koncentraciji, $0,25 \mathrm{ml}$ v $5 \%$ koncentraciji,
$0,125 \mathrm{ml}$ $5 \%$ koncentraciji, $0,062 \mathrm{ml}$ v $5 \%$ koncentraciji in $0,25 \mathrm{ml}$ v 2,5\% koncentraciji), kofeinom $(0,25 \mathrm{ml}$ v $10 \%$ koncentraciji, $0,125 \mathrm{ml}$ $\mathrm{v} 10 \%$ koncentraciji in $0,25 \mathrm{ml} \quad \mathrm{v} \quad 5 \%$ koncentraciji) in pripravkom Pirimor 50 WG $(0,25 \mathrm{ml}$ v $10 \%$ koncentraciji, $0,125 \mathrm{ml}$ v $10 \%$ koncentraciji, $0,062 \mathrm{ml}$ v $10 \%$ koncentracij,

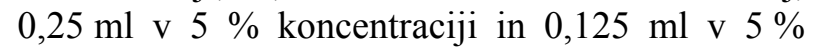
koncentraciji). Najboljše limacidno delovanje na lazarje smo dosegli z natrijevim dodecil sulfatom $\mathrm{v}$ 2,5\% koncentraciji (Verlič, 2012).

V laboratorijskem poskusu smo preučevali vpliv jakosti in napetosti električnega toka pri električni oviri, ki smo jo postavili z namenom preprečevanja prehoda polža (Arion spp.) $\mathrm{k}$ viru hrane (Laznik in sod., 2011). Preučevali smo napetost (2 V, 4 V, 6 $\mathrm{V}, 8 \mathrm{~V}$ in $10 \mathrm{~V}) \mathrm{v}$ kombinaciji z jakostjo $(0,1 \mathrm{~mA}$, $0.01 \mathrm{~mA}$ in $0.001 \mathrm{~mA}$ ). Rezultati naše raziskave so pokazali, da na uspešnost ovire vplivata oba dejavnika, tako jakost kot napetost el. toka. Pri najnižji napetosti $(2 \mathrm{~V})$ je oviro prestopilo $41 \%$ preučevanih polžev, pri najvišji napetosti $(10 \mathrm{~V})$ pa je oviro prešlo le $1 \%$ polžev. Do podobnih ugotovitev smo prišli tudi pri jakosti električnega toka. Najboljšo kombinacijo je predstavljalo razmerje $10 \mathrm{~V}$ in $0.01 \mathrm{~mA}$, kjer nismo zabeležili prehoda polžev čez oviro (Laznik in sod., 2011).

\section{ZAKLJUČEK}

Zatiranje gospodarsko pomembnih škodljivcev v kmetijstvu poteka predvsem s kemičnimi sredstvi za varstvo rastlin, ki pa imajo lahko na okolje tudi negativne vplive (Hata in sod., 1997; Henderson in Triebskorn, 2002). Za številne aktivne snovi so raziskovalci ugotovili, da izkazujejo neciljno delovanje na organizme (Martin, 1993; Purvis, 1996). Zaradi teh dejstev in vedno večje okoljske osveščenosti in skrbi za okolje, raziskovalci širom sveta iščejo načine v varstvu rastlin, ki so okoljsko sprejemljivi in nimajo negativnih vplivov na okolje in ljudi (Laznik in sod., 2011). Z ustrezno obdelavo tal lahko pripomoremo $\mathrm{k}$ zmanjšanju številčnosti polžev, $\mathrm{z}$ drugimi okoljsko sprejemljivimi ukrepi njihovega zatiranja, nekateri med njimi so predstavljeni v prispevku, pa lahko vplivamo na manjšo uporabo limacidov ali pa slednjih celo ni potrebno uporabiti.

\section{VIRI}

Ahmadi E. 2004. A faunal study on snails and slugs on canola as a second cropping in pady fields in Guilan and Mazandaran provinces. J Agric Sci, 1: 69-82 [In Persian].

Burnie D. 2001. Ilustrirana enciklopedija živali. Učila, založba, d.o.o., Tržič: 20 str.
Dmitrieva E.F. 1978. The influence of temperature and moisture of the upper soil layer on the hatching intensity of the slug Deroceras reticulatum Müller. Malacolog Rev, 11: 81-82.

Esenko I. 2008. Sto vrtnih živali na Slovenskem, 1. Izdaja. Prešernova družba d.d., Ljubljana: 244 str.

Acta agriculturae Slovenica, 107 - 2, september 2016 
Frank T. 1998. Slug damage and numbers of the slug pests, Arion lusitanicus and Deroceras reticulatum, in oilseed rape grown beside sown wildflower strips. Agric Ecosyst Environ, 67: 67-78. Doi: 10.1016/S0167-8809(97)00108-4

Godin D. 1983. Pest slugs and snails. Springer-Verlag, Berlin. 172 str. Doi: 10.1007/978-3-642-68797-6

Hammond R.B., Beck T., Smith J.A., Amos R., Barker J., Moore R., Siegrist H., Slates D., Ward B. 1999. Slugs in conservation tillage corn and soybeans in the Eastern corn belt. J Entomol Sci, 4: 467-478.

Hata T.Y., Hara A.H., Hu B.K.S. 1997. Molluscicides and mechanical barriers against slugs Vaginula plebeia Fischer and Veronicella cubensis (Pfeiffer) (Stylommatophora:Veronicellidae). Crop Prot, 16: 501-506. Doi: 10.1016/S0261-2194(97)00034-3

Henderson I., Triebskorn R. 2002. Chemical control of terrestrial gastropods. V: Molluscs as crop pests (Ur. G.M. Barker). CABI Publishing, Wallingford, UK: 1-31. Doi: 10.1079/9780851993201.0001

Kozłowski J. 2000. Reproduction of Arion lusitanicus Mabille, 1868 (Gastropoda: Pulmonata: Arionidae) introduced in Poland. J Plant Prot Res, 8: 87-94.

Kozłowski J., Kozłowska M. 1998. Food preferences of the slug Arion lusitanicus Mabille (Gastropoda: Stylommatophora) in south-east part in Poland. J Plant Prot Res, 38: 81-83.

Kozłowski J., Sionek R. 2000. The rate of egg laying and hatching of the slug Arion lusitanicus Mabille, a pest of arable crops. J Plant Prot Res, 40: 162167.

Laznik Ž., Trdan S. 2009. Parazitske ogorčice polžev. Acta agriculturae Slovenica, 93: 87-92.

Laznik Ž., Križaj D., Trdan S. 2011. The effectiveness of electrified fencing using copper electrodes for slug (Arion spp.) control with direct electric current and voltage. Span J Agric Res, 9: 894-900. Doi: 10.5424/sjar/20110903-412-10

Martin T.J. 1993. The ecobiological effects of arable cropping including the non-target effects of pesticides with special reference to methiocarb pellets (Draza, Mesurol) used for slug control. Pflanzenschutz-Nachr Bayer, 46: 49-102.

Mihičinac, M. 2010. Laboratorijsko preučevanje učinkovitosti različnih snovi za zatiranje lazarjev
(Arion spp., Gastropoda, Arionidae). Dipl. delo, Biotehniška fakulteta, Ljubljana: 36 str.

Milevoj L. 2007. Kmetijska entomologija (splošni del). Ljubljana, Biotehniška fakulteta Univerze v Ljubljani: 182 str.

Ortan M. 2014. Zatiranje polžev. Kmetovalec, 6-7: 34.

Prior D.J. 1985. Water regulatory behaviour in terrestrial gastropods. Biol Rev, 60: 403-425. Doi: 10.1111/j.1469-185X.1985.tb00423.x

Purvis G. 1996. The hazard posed by methiocarb slug pellets to carabid beetles: understanding population effects in the field. V: Slug and snail pests in agriculture (Henderson I.F., ur). BCPC Monograph No. 66, British Crop Production Council: 189-196.

Resnik, S. 2015. Preučevanje kontaktnega delovanja izbranih okoljsko sprejemljivih snovi na lazarje (Arion spp., Gastropoda, Arionidae) v laboratorijskem poskusu. Dipl. delo., Biotehniška fakulteta, Ljubljana: 40 str.

Ryder T.A., Bowen I.D. 1977. The slug foot as a site of uptake of copper molluscicide. J Invertebr Pathol, 30: 381-386. Doi: 10.1016/0022-2011(77)90149-5

Schüder I., Port G., Bennison J. 2003. Barriers, repellents and antifeedants for slug and snail control. Crop Prot, 22: 1033-1038. Doi: 10.1016/S0261-2194(03)00120-0

Šušek A. 2015. Zelena pomlad. Moj mali svet, 3-4: 25.

Vakselj N. 1992. Škodljive vrste polžev (Gastropoda) in njihovo zatiranje. Diplomska naloga. Ljubljana, BF, Oddelek za agronomijo: $35 \mathrm{str}$.

Verlič, D. 2012. Laboratorijsko preučevanje limacidnega delovanja izbranih snovi na lazarje (Arion spp., Gastropoda, Arionidae). Dipl. delo, Biotehniška fakulteta, Ljubljana: 28 str.

Wilson M.J., Glen D.M., George S.K., Butler R.C. 1993. The rhabditid nematode Phasmarhabditis hermaphrodita, as a potential biocontrol agent for slugs. Biocontrol Sci Technol, 3: 503-511. Doi: 10.1080/09583159309355306

Young A.G., Port G.R. 1989. The effect of microclimate on slug activity in the field. I. Henderson (Ed.) British Crop Protection Council Monograph No. 41, Slugs and snails in world agriculture: 263-269. 